\title{
Reflexões sobre duas crises econômicas no Império Português (1688 e 1770)*
}

\section{Reflections on two economic crisis in Portuguese Empire (1688 and 1770)}

\author{
MAXIMILIANO M. MENZ** \\ Professor do Departamento de História \\ Universidade Federal de São Paulo \\ Jovem Pesquisador da FAPESP \\ maxmacmenz@hotmail.com
}

RESUMO O artigo compara duas crises no Império português e discute os meios pelos quais ocorreram as subsequentes recuperações. Deste modo, procura-se revelar certas particularidades das economias do açúcar e do ouro e os seus modos de articulação com o resto do Império.

Palavras-chave crise, Império Português, açúcar, ouro

ABSTRACT The article compares two crises in the Portuguese Empire and discusses the means by which occurred the subsequent recoveries. Thus, it seeks to reveal some details of the economies of sugar and gold and their modes of interaction with the rest of the Empire.

Keywords crisis, Portuguese Empire, sugar, gold

* Artigo recebido em: 01/05/2011. Aprovado em: 11/03/2012.

** O autor agradece aos alunos André Filippe de Mello e Paiva, Guilherme Conigiero e Felipe Melo por ajudarem na coleta dos dados utilizados no artigo. 
Neste ensaio, discuto duas crises econômicas que ocorreram no Império português em dois momentos distintos, 1677-1688 e 1765-1777. Trata-se de um estudo inspirado pelas obras de Vitorino Magalhães Godinho e Ruggiero Romano, o primeiro pela proposta original de comparação entre as referidas crises; o segundo, pelos trabalhos clássicos sobre a crise do século XVII. ${ }^{1} \mathrm{O}$ tema pode parecer pouco usual e a referência a dois grandes historiadores, ligados à história econômica francesa e não à New Economic History, explicita a preferência por problemas historiográficos "fora de moda". No entanto, quero defender sua atualidade, pois a recente crise do capitalismo e os seus desdobramentos desiguais e ainda obscuros nas diferentes regiões do mundo voltam a tornar atrativo o estudo das conjunturas econômicas. Acredito que o estudo comparado das crises, em dois momentos muito distintos no que diz respeito à organização institucional do Império e da própria produção colonial dominante, permitirá compreender mais bem as dinâmicas da economia açucareira e da mineração. Além disso, os mecanismos das recuperações econômicas permitirão colocar em perspectiva a racionalidade mais geral do próprio Império português.

Ademais, nunca foi tão apropriado repensar as conjunturas econômicas do Império português, tendo em vista o grande número de séries econômicas que vem sendo publicado nos últimos tempos. Destaca-se particularmente a publicação dos estudos de Ângelo Carrara sobre a fiscalidade no Estado do Brasil que permite repensar certas questões com dados e hipóteses novos. ${ }^{2}$

O método que seguirei aqui é inspirado nas obras dos historiadores supracitados, além de Fernand Braudel e o velho Ernest Labrousse. Ou seja, a análise das séries econômicas deve gerar as perguntas enquanto que as hipóteses explicativas serão exploradas a partir das próprias séries, da bibliografia e da documentação. As seguintes séries fundamentaram a discussão das duas conjunturas: dízimos e arrecadação do Estado do Brasil no século XVII, produzidas por Carrara; preços do açúcar no Brasil, por Schwartz; exportações angolanas de escravos, por José Curto; exportações de tabaco, por Nardi; produção de ouro, por Noya Pinto; importações de escravos pelo Brasil, por Florentino, Ribeiro e Silva; remessas de metais preciosos a Portugal, por Souza; além das séries do Transatlantic Slave Trade Database (TSTD). Também elaborei uma série de dízimos para Rio de Janeiro, Bahia e Pernambuco para o período entre as décadas de 1750

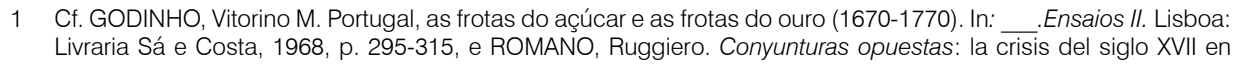
Europa e Hispanoamérica. Mexico: FCE, 1993.

2 CARRARA, Angelo. Receitas e despesas da Real Fazenda no Brasil, século XVII. Juiz de Fora, MG: Editora da UFJF, 2009. 
e 1770 reunindo dados publicados e originais. Parte destes dados pode ser encontrada num apêndice final. ${ }^{3}$

Antes de iniciar, penso que é necessário definir os conceitos que permitam delimitar o estudo. Sigo aqui F. Braudel, que costumava dizer que a "a vida dos homens flutua (...) ao sabor de movimentos periódicos" e que o conjunto destes movimentos é a conjuntura. Trata-se, como reconhece Braudel, de um conceito genérico, assim o "movimento oscilatório de conjunto foi divido em movimentos particulares", daí a proliferação de conceitos da história econômica do século passado, procurando interpretar diferentes durações e causas: Kuznet, Kondratieff, Juglar, Labrousse. ${ }^{4}$ Como ficará claro no texto, as duas conjunturas possuem durações diversas e relações bastante distintas com as estruturas econômicas atlânticas. Parece-me, portanto, ocioso, delimitá-las a priori, pois no desenvolvimento deste ensaio deverão ser esclarecidas suas causalidades e temporalidades.

Já o conceito de crise pode ser entendido de seu modo mais lato: por um desequilíbrio econômico entre oferta e demanda. As conjunturas de crise discutidas foram, portanto, conjuntos de "movimentos para baixo" na atividade econômica motivados pelo desequilíbrio entre oferta e demanda. Contudo, é preciso lembrar o velho Marx: a situação de "equilíbrio" é uma ilusão de Jean Baptiste Say: os desequilíbrios são "imanentes" à economia do mercado; a todo o tempo se produz "mais" ou "menos" do que a demanda efetiva e o "equilíbrio" só ocorre ex post. Existem, entretanto, momentos em que estes desequilíbrios são mais graves, paralisando e contagiando diversas atividades econômicas, expandindo-se no tempo e no espaço. ${ }^{5}$

No final do século XVII e no terceiro quarto do século XVIII ocorreram crises generalizadas, verdadeiras crises do Império português pela sua extensão geográfica. Como pretendo mostrar, as duas crises repercutiram na metrópole, afetando principalmente o fisco, e na colônia, mas estiveram ligadas de modo distinto à atividade básica colonial: o açúcar no século XVII e o ouro no século XVIII.

Um último esclarecimento formal: apesar de tratar-se de um ensaio baseado principalmente nos trabalhos de Ângelo Carrara, foram utilizados documentos e alguns dados novos para sustentar as partes mais "polêmicas" do texto.

3 As referências completas serão citadas oportunamente. Ver também o apêndice.

4 BRAUDEL, Fernand. Civilização material, economia e capitalismo: Vol. III, O tempo do Mundo. São Paulo: Martins Fontes, 1998, vol. III, p. 59. Ver também LABROUSSE, Ernest. Fluctuaciones económicas e historia social. Buenos Aires: Editorial Tecnos, 1973.

5 As reflexões marxianas sobre o desequilíbrio estão sumariadas em GRESPAN, Jorge. O negativo do Capital. São Paulo: Hucitec, 1999, passim. 
Para tratar da crise do final do século XVII, começo pelo estudo recente do Prof. Ângelo Carrara. Centrando a sua análise nas receitas e despesas do Estado Brasil, Carrara observa que o século XVII foi marcado pelo aumento crescente das despesas, em razão das pressões militares. Mesmo depois da década de 1650, os gastos seguiram determinando a arrecadação: a guerra dos Bárbaros, a cobrança do dote do casamento da Rainha da Inglaterra e a Nova Colônia de Sacramento não permitiram um alívio nas contas da Real Fazenda.

O problema, porém, foi agravado pela arrecadação. Os anos entre 1688-1693 foram de depressão severa, com uma queda acentuada na arrecadação dos dízimos, pelo menos em Pernambuco e na Bahia. No entanto, como observa o autor, a queda não foi tão generalizada assim, pois no Rio de Janeiro, desde 1677, observa-se uma tendência ao crescimento na arrecadação.

Sendo assim, são duas as conclusões de Carrara: que os problemas no nordeste teriam origem no movimento das colheitas do açúcar; a quebra de 1688 explicar-se-ia pelo mal da bicha e pela seca que afetaram a produção açucareira e não por uma redução nos preços. A expansão nos dízimos do Rio seria um reflexo na quebra da produção de Pernambuco e da Bahia. ${ }^{6}$ Assim, a crise no nordeste seria de oferta e não uma crise de demanda; sua origem estaria na produção de açúcar brasileira.

A opinião de Carrara contrasta com as conclusões do estudo clássico de Godinho. Segundo o historiador português, a década de 1680 foi afetada pela queda nos preços dos produtos tropicais em Portugal, refletindo uma redução na demanda por estes produtos na Europa. A ideia de Godinho é coerente com as interpretações canônicas sobre a economia do açúcar: esta era "dependente" em seu sentido mais profundo, a decisão de investir era determinada pelos preços externos, daí os ritmos da economia colonial serem compassados pela demanda européia. ${ }^{7}$

Ademais, se o problema estivesse apenas na oferta do açúcar, como sugere a análise de Carrara, os preços praticados no Brasil deveriam ter subido, mas permaneceram baixos até 1695, de acordo com a série de Stuart Schwartz, acompanhando o mercado externo. ${ }^{8}$ Em outras palavras, a redução na oferta do açúcar da Bahia e de Pernambuco não bastou para que os preços no Brasil reagissem. Também seria improvável que uma redução na produção do açúcar no Brasil tivesse grande influência sobre os preços, pois no final do século XVII a produção nas Antilhas já era fundamental para a constituição da oferta mundial do açúcar. ${ }^{9}$

CARRARA, Angelo. Receitas e despesas da Real Fazenda no Brasil, século XVII, p.116-119.

FURTADO, Celso. Formação econômica do Brasil. São Paulo: Companhia Editora Nacional, 1976, passim.

SCHWARTZ, Stuart. Segredos internos. São Paulo: Companhia das Letras, 1988, p.401.

9 Ver BLACKBURN, Robin. A construção do escravismo no Novo Mundo: do Barroco ao moderno, 1492-1800. Rio de Janeiro: Record, 2003, p.489. 
Os testemunhos da época também se concentram sobre o problema dos preços, como escreveu o provedor da fazenda Francisco Lamberto a respeito do baixo valor do contrato dos dízimos da Bahia:

se rematou este contrato a respeito da que teve o preço do açúcar que chegou a arrematar-se, em diversas execuções, de quatro até cinco tostões por arroba do branco, e pelos mesmos preços se vendeu também muito, e se teme o mesmo com a presente safra se suceder como se receia que não venha a frota a carregá-los. ${ }^{10}$

Como mostraram os trabalhos de Vitorino Magalhães Godinho e Borges de Macedo, nos quadros do Império português, a crise manifestou-se primeiro em Portugal, já no final da década de 1660. Trata-se do efeito de uma redução geral nos preços dos produtos coloniais, açúcar, tabaco e cravo; diminuiu ainda o comércio de sal português que trazia saldos de prata ao Reino. O resultado foram as leis pragmáticas que procuraram limitar o luxo na corte e reduzir as importações e a política manufatureira do Conde de Ericeira. As raízes da crise, para Godinho, seriam a baixa secular do Seiscentos e a concorrência no mercado de produtos coloniais, reflexo da transferência holandesa para as Antilhas da tecnologia açucareira. ${ }^{11}$

A crise, portanto, não era apenas do açúcar: dado o caráter diversificado dos negócios dos grandes capitalistas do Antigo Regime, a baixa no sal e no cravo pode ter contaminado o negócio do açúcar. Assim, uma operação que visava à pulverização dos riscos nas conjunturas positivas, potencializava os mesmos durante a conjuntura depressiva, lembrando a dialética negativa de Marx.

Faltos de moeda em Lisboa, em razão da queda dos principais produtos do Império, os grandes atacadistas reinóis buscavam liquidez na colônia, executando as dívidas e não aceitando o pagamento em gêneros da terra em suas exportações ao Brasil; de modo que a ausência de dinheiro no Reino, manifestada no final da década de 1660, foi exportada para o Brasil como mostram as repetidas queixas da câmara da Bahia entre 1678 e $1681 .{ }^{12}$

Na verdade, a tendência negativa dos preços de açúcar iniciou efetivamente em 1614 de modo praticamente sincrônico com a crise europeia do século XVII que, segundo R. Romano, teve como marco inicial os anos de 1619-1622. Os anos positivos em meados do século e a expansão açucareira para as outras zonas (como o Rio de Janeiro) foram provocados pela guerra com os flamengos:

10 Arquivo Histórico Ultramarino (AHU), Avulsos, Bahia/LF, cx. 28, doc. 3492, Francisco Lamberto, 04/12/1688.

11 Cf. GODINHO, Vitorino M. Portugal, as frotas do açúcar e as frotas do ouro, passim, e MACEDO, Jorge B. Problemas de história da indústria portuguesa no século XVIII. 2 ed. Lisboa: Querco, 1982, p.22-25.

12 O problema é resumido nas consultas do Conselho Ultramarino de 06/08/1680 e 04/02/1681; AHU, Bahia/LF, cx.25, docs. 2988 e 2989 
A perda de uma das parcelas mais produtivas do território. (...) A súbita alteração dos preços do açúcar na Europa e a promessa de receitas chorudas, num contexto que permitia inflacionar o preço do transporte, estimularam a renovação dos agentes mercantis e armadores. (...) Os preços voltavam a adquirir diferenciais cativantes, quando a navegação, sujeita interrupções pelos bloqueios do inimigo ou por medidas de segurança ditadas pelo governador geral. ${ }^{13}$

Contudo, como bem notou Carrara, a queda dos preços por si não permite explicar a evolução divergente do Rio de Janeiro entre 1677 e 1688. ${ }^{14}$ Se a produção açucareira do Rio conseguiu operar positivamente num momento de baixa geral dos preços, em oposição à produção nordestina, significa que seus custos de operação no período de 1670-1680 eram relativamente mais baixos. ${ }^{15}$

Mas quais eram estes custos? Em documento de 1672, os senhores de engenho da Bahia queixavam-se a respeito do estado da produção canavieira e apontavam para três causas da "atenuação" da lavoura: "pela carestia dos escravos que a cultivam, segundo pelos fornecimentos, e $3 a$ pelos grandes impostos que tem". ${ }^{16}$

Um diferencial nos preços de escravos, nos impostos e no custo dos "fornecimentos" (ou seja, nos insumos dos engenhos) pode ter favorecido o Rio em relação à Bahia e Pernambuco. Uma primeira suposição seria que o uso da cachaça pelos comerciantes do Rio no tráfico de Angola teria barateado a importação de escravos; esta ideia seria sustentada pelas reflexões de L. F. Alencastro que considera que a jeribita permitira aos brasílicos escapar-se em parte dos flagelos da crise do século XVII. Mas, de acordo com José Curto, no final do século XVII a cachaça era fornecida principalmente por Bahia e Pernambuco, regiões que enfrentavam a depressão na década de $1680 .{ }^{17}$ Tampouco os números do tráfico permitem

13 COSTA, Leonor. O transporte no Atlântico e a Companhia Geral do Comércio do Brasil, 1580-1663. Lisboa: CNCDP, 2002, p.218. F. Mauro observou outro efeito indireto da guerra Atlântica: o renascimento na produção do açúcar da madeira durante a década de 1640, MAURO, Frédéric. Portugal, o Brasil e o Atlântico 1570-1670. Lisboa: Estampa, 1997, v.1, p.249-250.

14 Jucá Sampaio também notou o deslocamento da economia açucareira do Rio frente à crise do século XVII, mas sua interpretação dos números é que "somente uma forte vinculação entre comércio e agricultura, com transferência contínua de recursos do primeiro para a segunda, permitiria que ela mantivesse seu dinamismo em meio a uma conjuntura desfavorável". Em suma, o autor procura explicações estruturais, a autonomia da economia colonial, para a relativa descolagem do Rio e supõe que os negociantes continuariam investindo em uma atividade em baixa. Só que Sampaio não considera que a economia do nordeste entrou em crise no mesmo período, o que mostra que o comportamento da produção açucareira do Rio respondia aos desdobramentos desiguais de uma conjuntura de crise, ou seja, fatores de médio prazo (a seca e epidemia que atingiram de modo mais violento a produção de alimentos no nordeste) favoreceram o Rio em detrimento de Pernambuco e Bahia. Cf. SAMPAIO, Antonio Carlos Jucá. Na encruzilhada do Império: hierarquias sociais e conjunturas econômicas no Rio de Janeiro, 1650-1750. Rio de Janeiro: Arquivo Nacional, 2002, p.114.

15 Ressalte-se que a documentação do Rio de Janeiro também registra queixas no que diz respeito ao preço do açúcar, a ausência de moeda e as epidemias, de modo que a crise na praça também foi sentida, ainda que de modo menos violento do que na Bahia e Pernambuco; ver, por exemplo: AHU, Rio de Janeiro, cx. 4, doc. 436, 06/05/1680, AHU, Rio de Janeiro, cx. 6, doc. 565, 26/09/1692, AHU, Rio de Janeiro/CA, cx.9, docs. 1766-1769, 02/04/1691.

16 AHU, Bahia/LF, cx. 21, doc. 2489, 24/08/1672.

17 CURTO, José. Álcool e escravos: o comércio luso-brasileiro do álcool em Mpinda, Luanda e Benguela durante o tráfico atlântico de escravos (c. 1480-1830) e o seu impacto nas sociedades da África Central e Ocidental. Lisboa: 
esta conclusão, ainda que a participação dos governadores brasílicos de Angola, ligados à capitania de Pernambuco, tenha facilitado a reconstrução do parque açucareiro da capitania. ${ }^{18}$

Outra alternativa, ainda no que diz respeito ao diferencial no custo dos escravos, seria a obtenção de escravos índios, mais baratos, no sertão paulista. Trata-se de uma ideia razoável, ainda se descontados os cálculos de S. Schwartz que mostram como a diferença do preço do escravo africano refletia a diferença em sua produtividade. ${ }^{19}$ Mas a verdade é que, apesar da importância da mão-de-obra indígena durante a montagem do complexo açucareiro no Rio, especialmente se considerado o bloqueio sobre Luanda na década de 1640, o tempo de trabalho índio barato e abundante já havia acabado. ${ }^{20}$

Outra causa levantada pela câmara para o problema da lavoura eram os impostos. A tributação incidia de modo desigual sobre a produção açucareira, mas no atual estado da pesquisa parece-me impossível um cálculo exato sobre o peso relativo dos impostos sobre o açúcar de cada capitania.

Podemos apenas fazer algumas estimativas a este respeito. O donativo para o dote da rainha da Grã Bretanha e paz de Holanda era um dos impostos mais importantes no final do século XVII e a sua cobrança era muito desigual. O valor a ser pago pela Bahia era de 80.000 cruzados anuais, enquanto que o Rio de Janeiro deveria pagar 26.000 e Pernambuco, ainda se recuperando da guerra de restauração, pagaria 25.000 anuais. Esta proporção de 3 por 1 parece refletir os rendimentos dos dízimos das capitanias, ou seja, a Bahia pagava mais, mas a sua maior produção poderia, em princípio, absorver os custos deste imposto. Só que o modo como foram feitos os pagamentos variou bastante no tempo e em cada capitania; por exemplo, nos anos críticos de 1687-89 a Câmara do Rio de Janeiro simplesmente não cobrou as contribuições. ${ }^{21}$

No conjunto, parece que os açúcares do Rio eram menos gravados, pagando apenas o dízimo - além dos impostos indiretos. Pernambuco, por sua vez, pagava ainda 80 réis por caixa ao donatário (cobrança revertida à Fazenda Real), mais um subsídio de 60 réis na arroba do açúcar branco e 30 réis no mascavado. Na Bahia, pagavam-se mais dois réis por caixa exportada. ${ }^{22}$ As diferenças existiam, mas não creio que favorecessem de

Vulgata, 2002, p.154 e quadro II.

18 LOPES, Gustavo Acioli. Brazil's colonial economy and the Atlantic slave trade: supply and demand. (artigo inédito), p.10-11; e LOPES, Gustavo Acioli. Negócio da Costa da Mina e comércio atlântico: tabaco, açúcar, ouro e tráfico de escravos, Pernambuco (1654-1760). São Paulo: Universidade de São Paulo, 2008. (História, Tese de doutorado), anexo II.

19 SCHWARTZ, Stuart. Segredos internos, p.72.

20 MONTEIRO, John. Negros da terra. São Paulo: Companhia das Letras, 1994, p.189.

21 CARRARA, Angelo. Receitas e despesas da Real Fazenda no Brasil século XVII, p.56

22 CARRARA, Angelo. Receitas e despesas da Real Fazenda no Brasil século XVII, passim. 
modo tão decisivo ao Rio de Janeiro, particularmente se comparado com a Bahia.

Retomando as queixas da câmara, o outro fator para a atenuação da lavoura eram os "fornecimentos", ou seja, os insumos da produção açucareira. À primeira vista, tratando-se de produção escravista, os maiores custos, além dos próprios escravos, era a sua alimentação. Contudo, os engenhos de açúcar possuíam uma contabilidade mais complexa, incluindo salários, combustíveis, escravos, alimentos e equipamentos. ${ }^{23}$ De todos estes fatores, os alimentos deveriam ser os mais sujeitos a variações temporais e regionais, dada a usual inelasticidade da demanda por estes produtos; além disso, deveriam afetar os custos dos lavradores de cana de modo mais decisivo, já que estes não tinham gastos com lenha e salários.

O diferencial na alimentação dos escravos é uma hipótese atraente. Enquanto que o abastecimento da Bahia e de Pernambuco estava ligado ao sertão do São Francisco e do Açu, o Rio de Janeiro era abastecido pela sua hinterland e também por São Paulo. O período entre 1670 e 1680 é marcado pelos levantes dos índios tapuias na região, no episódio conhecido como Guerra dos Bárbaros, além da já referida seca, que seguramente abalaram o mercado de carnes e de farinha mandioca no nordeste. ${ }^{24}$ Às eventuais perdas nas covas de mandioca, é preciso considerar o peso do sustento das tropas que combatiam os índios sobre o mercado de alimentos.

Em 1686, a Câmara de Salvador pediu providências para que os moradores do Recôncavo fossem obrigados a plantar 500 covas de mandioca por escravo. ${ }^{25}$ E exatamente em 1688 a Câmara de Camamu na Bahia reclamava do governador por taxar a venda da farinha de mandioca desde 1683. ${ }^{26}$ Informando o requerimento dos camaristas, o chanceler da relação da Bahia, Manuel Carneiro de Sá, acusava os lavradores de farinha de mandioca de se mancomunarem e que "Ihe subiam o preço (...) a um tal excesso que se vendia o sírio da farinha a cinco ou seis patacas". ${ }^{27}$

No mesmo período, para o Rio de Janeiro não são muitas as informações sobre o abastecimento, particularmente no que diz respeito às condições relativas da capitania frente às da Bahia e de Pernambuco. Trata-se aqui de reconstituir um pequeno quebra-cabeça, tendo em vista que não existem séries de preços de alimentos coloniais no século XVII. Em um documento de 1702, a câmara do Rio contestou o Alvará que obrigava os senhores

23 Stuart Schwartz, analisando a contabilidade de diversos engenhos baianos entre os séculos XVII e início do XIX, conclui que os alimentos eram o $4^{\circ}$ elemento, em ordem de importância, nas despesas de um engenho (atrás dos salários, combustíveis e escravos). Mas, naturalmente, a estrutura de custos de cada engenho variava muito; SCHWARTZ, Stuart. Segredos internos, p.192.

24 PUNTONI, Pedro. A guerra dos bárbaros: povos indígenas e a colonização do sertão nordeste do Brasil, 1650/1720. São Paulo: Hucitec/Edusp, 2002, p.151. Ver também CARRARA, Angelo. Receitas e despesas da Real Fazenda no Brasil século XVII, p.111.

25 AHU, Avulsos, Bahia/LA, cx. 28, docs. 3421-3422, 09/08/1687

26 AHU, Avulsos, Bahia/LF, cx. 28, doc. 3.473, 28/07/1688.

27 AHU, Avulsos, Bahia/LF, cx. 28, doc. 3.474, 12/07/1689 
de engenho ao cultivo de 500 mandiocas por escravo, argumentando que o diploma havia sido uma resposta à câmara de Salvador onde se experimentava escassez de farinha, enquanto que no Rio tudo seria diferente

porque é certo que as Mandiocas de que se sustenta e as que the abastam e muitas vezes sobram: todas se plantam no recôncavo desta mesma cidade pelos rios acima Aguassú, Inhumirim, Morobohy, Magé, Sernambitina, Guapehy, Surahi e Macací em que se costumam comumente lavrar mandiocas de cujas terras são possuidores vários donos e nelas não há engenhos que prejudiquem as suas plantas e delas pode vir a esta cidade farinhas em tanta quantidade e abundância que sustente o Povo largamente e de fácil provimento às frotas sem demora. ${ }^{28}$

Só que alguns relatos sobre a década de 1680 não são positivos; particularmente os socorros à Colônia de Sacramento afetavam a situação do abastecimento na capitania. Na certidão do padre Matheus de Moura, era elencado o envio de navios para a Colônia como a primeira causa da decadência do Rio de Janeiro, pois estes carregavam no local os "mantimentos e mais gêneros" e os moradores viam-se obrigados a "comprar por seis aqueles gêneros que antes compravam por dois". ${ }^{29}$ A carestia no Rio estava, portanto, associada a momentos de curta duração, pela partida de embarcações para o sul, e não a uma conjuntura mais longa como parece ser o caso do nordeste: Francisco Carlos Teixeira da Silva registrou em seu quadro de crises de subsistência apenas uma carestia para o Rio de Janeiro no ano de 1688 e uma série de fomes e carestias na Bahia entre 1687 e 1693. ${ }^{30}$ Aliás, o colapso alimentício da Bahia em 1688 pode ter fragilizado o mercado de mandioca na baía de Guanabara. ${ }^{31}$

Seja como for, as fontes sugerem que o problema do abastecimento foi relativamente menor no Rio. Basta considerar que, segundo o desembargador Manuel Carneiro de Sá, o preço do sírio da farinha mandioca em Salvador teria ultrapassando em mais de 600 réis a arroba do açúcar. Teríamos, assim, uma "tesoura de preços" na Bahia e em Pernambuco, demarcada pelo aumento dos custos e pela queda no produto, favorecendo a produção no Rio de Janeiro. Com custos mais competitivos, a produção açucareira do Rio teria respondido à queda nos preços com um aumento no volume, daí a tendência positiva nos dízimos. ${ }^{32}$

28 AHU, Avulsos, Rio de Janeiro/CA, cx. 13, docs. 2672-2673, 06/11/ 1702

29 AHU, Avulsos, Rio de Janeiro/CA, cx. 9, docs. 1.766-1.769, 28/03/1691.

30 SILVA, Francisco Carlos Teixeira da. Morfologia da escassez: crises de subsistência e política econômica no Brasil colônia (Salvador e Rio de Janeiro, 1680-1790). Niterói, RJ: Universidade Federal Fluminense, 1990 (História, Tese de doutorado), p.183-184.

31 Este foi o caso das crises de abastecimento do final do século XVIII, quando o colapso em Pernambuco provocou carestia no sul, cf. MENZ, Maximiliano. Entre Impérios. São Paulo: Alameda, 2009, p.127-157.

32 João Fragoso e Manolo Florentino afirmam que a empresa escravista poderia multiplicar a produção para enfrentar a queda nos preços externos; cf. FRAGOSO, João e FLORENTINO, Manolo. O arcaísmo como projeto: mercado atlântico, sociedade agrária e elite mercantil em uma economia colonial tardia Rio de Janeiro, c. 1790 - c. 1840.4 ed. revista. Rio de Janeiro: Civilização Brasileira, 2001, p.125. Esta operação, porém, dependia de circunstâncias muito específicas, como parece ser o caso da década de 1680. 
A causa estrutural da crise no nordeste seria a redução secular dos preços, motivada pela queda da demanda europeia; a causa imediata do colapso de 1688 seria o movimento das colheitas como argumenta Carrara, mas o centro desta redução estaria na produção para o abastecimento que, por sua vez, repercutiria sobre o açúcar.

O segundo ponto a ser discutido é a respeito dos mecanismos da recuperação econômica. Existem sinais de uma retomada nos preços no final da década de 1690 em razão dos sucessos militares no Atlântico. Além disso, como é bem sabido, o século XVIII é um século de expansão econômica na Europa e de aumento no consumo de produtos americanos, por isto uma recuperação na produção açucareira do Brasil era previsível, ainda que muito lenta e sujeita aos constrangimentos da multiplicação dos produtores na América.

No entanto, as séries que existem sugerem uma relativa estagnação na agricultura de exportação até o final do século XVIII. ${ }^{33}$ É que a recuperação esteve baseada na mudança do "centro dinâmico" da economia colonial, do litoral para o interior, do açúcar para o ouro; apesar da produção açucareira permanecer, as atividades ligadas ao ouro absorveram a maior parte dos capitais. Ou seja, a mudança do centro dinâmico gerou uma nova geografia e repercutiu sobre as capitanias do litoral, não apenas descapitalizando o açúcar, mas também favorecendo o tráfico de escravos e o comércio de importação.

Mas é importante lembrar que a economia mineradora possuía certas particularidades que a destacam das atividades agrícolas do litoral. Como lembra Carrara, com o ouro a produção colonial passou a responder às "demandas geradas pela circulação monetária correspondente à produção do ouro". ${ }^{34}$ Mais do que isto, o caráter altamente especulativo da produção de metais preciosos dava uma certa autonomia aos investimentos coloniais que não dependiam mais dos preços europeus. A prospecção e extração do ouro mantinham-se enquanto os custos da produção não ultrapassassem o seu produto; do mesmo modo seguiam os investimentos e a geração de demanda, ainda que a redução da lucratividade certamente tivesse como resultado uma desaceleração relativamente lenta. ${ }^{35}$

A natureza da produção de metais preciosos é decisiva na espacialidade da crise das décadas de 1760 e 1770: ao que tudo indica, iniciou no Brasil e não em Portugal, Carrara destaca que no começo da década de 1760, em Minas Gerais, já havia sinais da diminuição na produção aurífera,

33 Cf. CARRARA, Angelo. Receitas e despesas da Real Fazenda no Brasil, século XVIII, p.107; NARDI, Jean Baptiste. O fumo brasileiro no período colonial. São Paulo: Brasiliense, 1996, p.341.

34 CARRARA, Angelo Alves. Minas e currais: produção rural e mercado interno de Minas Gerais, 1674-1807. Juiz de Fora, MG: Editora da UFJF, 2007, p.60.

35 Furtado, falando sobre a produção do açúcar, deduzia que a decadência da produção se manifestava por um processo lento de diminuição no ativo da empresa, sem ocorrer uma mudança estrutural; cf. FURTADO, Celso. Formação econômica do Brasil, p.52. 
particularmente com a incapacidade dos contratadores em cumprir com os contratos ${ }^{36}$ Quase de imediato diminuem as cunhagens de ouro na Casa da Moeda de Lisboa. ${ }^{37}$

De fato, o estudo pioneiro de Noya Pinto mostra que o início da década de 1750 foi o ponto máximo na produção aurífera brasileira, superando as 15 mil quilogramas anuais; a partir daí, constata-se uma queda constante, alcançando as 8 mil quilogramas anuais nos anos de 1770. O fim da Guerra de Sete Anos na Europa em 1763 agravou o problema, reduzindo os preços do açúcar e afetando as exportações de produtos tropicais. Entre 1763 e 1768, não apareceram interessados para arrematar o contrato do dízimo do açúcar da Bahia, em Pernambuco houve uma queda muito clara, enquanto que no Rio de Janeiro a tendência à alta na arrematação do tributo, durante o período da guerra, foi interrompida (ver apêndice 1 , tabelas 2, 3, 4). ${ }^{38}$

A passagem da década de 1760 para 1770, aliás, foi um momento crítico, com a produção do ouro se reduzindo bastante. Tampouco as exportações dos produtos tradicionais da agricultura tropical se recuperaram da queda pós 1763, pois no início de 1770 exportava-se uma média anual de 226 mil arrobas de tabaco e pouco mais de 600 mil arrobas de açúcar anuais: números comparáveis aos da década de 1730. O tráfico de escravos, tanto em Angola como na Costa da Mina, caiu na década de 1770 (ver apêndice 2, gráficos 2 e 3). ${ }^{39}$

Trata-se, portanto, de uma crise generalizada, mas com algumas exceções notáveis. A economia da região do Amazonas foi particularmente favorecida pela expansão do tráfico de escravos e pelo avanço da agricultura de exportação naquela região. Pernambuco também demonstra resultados claramente positivos na década de 1770 no que diz respeito aos dízimos,

36 CARRARA, Angelo. Receitas e despesas da Real Fazenda no Brasil, século XVIII, p.57.

37 SOUZA, Rita M. Moeda e metais preciosos no Portugal Setecentista. Lisboa: Imprensa Nacional, 2005, p.223.

38 Cf. AHU, Bahia/CA, "Auto de arrematação do contrato dos dízimos reais e da resolução que sobre o mesmo tomou o Conselho da Fazenda por não haver arrematante que o tomasse", Bahia, 27 de e junho de 1764. doc. 6562. Anexo ao n. 6551. Infelizmente, tive de me basear unicamente no resumo do documento que consta em ALMEIDA, Eduardo Castro. Inventário dos documentos relativos ao Brasil existentes no Archivo de Marinha e Ultramar. Rio de Janeiro: Biblioteca Nacional, 1914, p.69, já que o documento inexplicavelmente não consta na coleção do Projeto Resgate.

39 Para a estimativa da produção aurífera, ver PINTO, Virgílio Noya. O ouro brasileiro e o comércio anglo-português. São Paulo: Companhia Editora Nacional, 1979, p.114, tabela 5. A respeito do tráfico de escravos ver FLORENTINO Manolo, RIBEIRO, Alexandre V. e SILVA, Daniel D. Aspectos comparativos do tráfico de africanos para o Brasil (séculos XVIII e XIX). Afro-Ásia, n. 31, p.83-126, 2004, gráfico 1; e, CURTO, José. Álcool e escravos: o comércio luso-brasileiro do álcool em Mpinda, Luanda e Benguela durante o tráfico atlântico de escravos (c. 1480-1830) e o seu impacto nas sociedades da África Central e Ocidental. Lisboa: Vulgata, 2002, quadros IV e VIII; The TransAltlantic Slave Trade Database, http://slavevoyages.org/tast/assessment/estimates.faces. Acesso em: 12 nov. 2009. Sobre o açúcar e o tabaco, ver ALDEN, Dauril. O período final do Brasil colônia, 1750-1808. In: BETHELL, Leslie. (dir.). História da América Latina. Vol. II. São Paulo: Edusp, 1999, p.566; e NARDI, Jean Baptiste. O fumo brasileiro no período colonial. Simonsen estima a exportação anual de açúcar do Brasil na década de 1770 entre 1.500.000 e 1.750.000 arrobas, números que são compatíveis aos apresentados pelo mesmo autor sobre o início do século XVIII; SIMONSEN, Roberto. História econômica do Brasil. 3 ed. São Paulo: Companhia Editora Nacional, 1957, tabela, p.144-145. 
isto em função do produto mais bem sucedido da diversificação agrícola, o algodão. ${ }^{40}$

Sobre a diversificação, aliás, é necessário dizer algumas palavras: a historiografia, pelo menos desde Caio Prado Jr., vem apontando para a importância do fenômeno no aftermath da depressão aurífera, de fato, ele existiu, já nos primeiros anos da década de 1770 os dízimos de Rio de Janeiro, Pernambuco e Bahia mostram uma pequena tendência ao crescimento, em reflexo à retomada dos conflitos europeus e a recuperação dos preços, no entanto, apenas Pernambuco mantém a tendência de modo claro (ver apêndice 1, tabelas 2,3 e 4) ${ }^{41}$. Ademais, os dados dos dízimos e do quinto do ouro revelam que as perdas com a produção mineral não foram compensadas (ver apêndice 1, gráfico 1). E os números do tráfico de escravos confirmam a estagnação do investimento no Estado do Brasil durante as décadas de 1760 e 1770.42

Outro ponto a ser esclarecido é o contraste entre as emissões e as remessas de ouro dos particulares para Portugal. Como escreve Rita Martins de Souza,

a partir de 1760, as emissões monetárias diminuem significativamente, coincidindo esta diminuição com o período em que a oferta interna de ouro (...) aumenta de forma relativamente oscilante nas três últimas décadas do século. Esta conclusão (...) encontra explicação no facto de a descida das emissões monetárias em Lisboa se apresentar relacionada com um quebra de emissões para o Estado, decorrente do menor afluxo de chegadas para este agente. Todavia, as remessas de ouro têm uma diminuição inferior à registada em termos de emissões monetárias em Lisboa, atingindo a amoedação no Rio de Janeiro montantes relativamente elevados que, como já vimos, teriam por destino o Reino. ${ }^{43}$

As causas deste fenômeno devem ser várias: é possível que a expansão da fronteira mineradora para zonas mais periféricas e de produção mais dispersa, como Goiás e Mato Grosso, tenha dificultado a arrecadação. ${ }^{44}$ Por um mapa geral de 1773 sabemos que a tendência da produção aurífera era positiva em Mato Grosso entre 1769 e $1772 .{ }^{45}$

40 Cf. PALACIOS, Guillermo. Cultivadores libres, Estado y crisis de la esclavitud en Brasil en la época de la Revolución Industrial. Ciudad de Mexico: FCE, 1998, passim.

41 Os dados de Seymour Drescher sugerem inclusive que na década de 1770 a participação do açúcar brasileiro no mercado norte-atlântico foi superior à década de 1780. Cf. DRESCHER, Seymour. Econocide: British slavery in the era of abolition. Pittsburgh: Univesity of Pittsburgh Press, 1977, p.48, table 11

42 Sobre a diversificação, cf. PRADO Jr., Caio Prado. História econômica do Brasil. 34 ed. São Paulo: Brasiliense, 1986, p.79-93; NOVAIS, Fernando. Portugal e o Brasil na crise do Antigo Sistema Colonial. 6 ed. São Paulo: Hucitec, 1995, p. 254-267; ARRUDA, José Jobson de. O Brasil no comércio colonial. São Paulo: Ática, 1980, p.604-630; e mais recentemente PESAVENTO, Fábio. Um pouco antes da Corte: a economia do Rio de Janeiro na segunda metade do Setecentos. Niterói, RJ: Universidade Federal Fluminense 2009. (História, Tese de doutorado).

43 SOUZA, Rita M. Moeda e metais preciosos no Portugal Setecentista, p.223.

44 Cf. PINTO, Virgílio Noya. O ouro brasileiro e o comércio anglo-português, p.111.

45 Segundo o "Mapa que demonstra o produto geral das Minas de Cuiabá e Mato Grosso desde o seu descobrimento", AHU, Avulsos, Mato Grosso, cx. 17, doc. 1054, 1773. 
Devemos ainda considerar o modelo explicativo para a produção aurífera proposto por Angelo Carrara: a paisagem agrícola da zona mineradora seria marcada pela presença de propriedades escravistas e camponesas. A redução na extração do ouro produziu o que Carrara chamou de desconcentração da produção rural, com a diminuição da escala da empresa escravista e com a pulverização da propriedade em torno de células camponesas. Esta circunstância explica em parte o crescimento constante da população de Minas Gerais, mesmo numa época de crise. Em 1766, a população da capitania era de 208.600 indivíduos, passando, em 1776, a 319.769 pessoas; isto com uma clara redução no tráfico negreiro como mostra a distribuição mais equilibrada de sexos entre a população negra e parda. ${ }^{46}$

Esta reconfiguração sócio-demográfica pode ter influenciado os trends da produção de ouro, particularmente pela substituição das grandes extrações auríferas pelos faiscadores. Estes elementos se aproximariam de um "cálculo econômico camponês", de modo que a coleta do ouro poderia continuar mesmo que, nos quadros de uma contabilidade escravista, os custos monetários superassem os ganhos com o metal, pois o objetivo da produção camponesa era o equilíbrio entre o trabalho de sua família e as suas necessidades de reprodução sociocultural. ${ }^{47}$

Também há de se considerar que as delongas nas correntes de crédito e na execução de dívidas levavam a uma assincronia entre compras e pagamentos, com espaços deveras alongados como demonstra a contabilidade da Companhia de Pernambuco. ${ }^{48}$ Parte das moedas remetidas aos particulares nas décadas de 1770 e 1780 poderia estar pagando compras de décadas anteriores.

À demora no pagamento das dívidas é preciso relacionar ainda o ritmo próprio da economia mineradora, já referido, em que os investimentos poderiam seguir apesar da redução na produção. Mas a lenta depressão teria efeito sobre a escala das atividades, marcando uma pulverização da extração, em que os grandes mineradores e o ouro em barra, seriam substituídos pelos faiscadores e o ouro em pó, de mais difícil fiscalização. ${ }^{49}$

Por estas hipóteses, o ouro remetido nas décadas posteriores a 1760 aos particulares no Reino seria, em parte, moeda antiga e ouro em pó transformado em moeda para a sua travessia Atlântica, que anteriormente

46 CARRARA, Angelo. Minas e currais, p.328-329. Em 1766, existiam 4,8 escravos homens para cada escrava muIher. O mapa de população de 1776 não registra o número de escravos, mas é possível uma aproximação pelo número de pardos e negros; assim, tem-se que eram 1,7 pardos ou negros para cada mulher parda ou negra. Naturalmente que os diferentes critérios de cálculo (escravos x pardos/negros) falsifica os resultados, mas, os mapas de população confirmam a pesquisa de Bergad com inventários; cf. BERGAD, L. Escravidão e história econômica: demografia de Minas Gerais. Bauru: Edusc, 2004, p.177-201).

47 Sobre o cálculo econômico camponês ver: KRIEDTE, Peter. Camponeses, senhores e mercadores: a Europa e a economia mundial, 1500-1800. Lisboa: Teorema, 1992.

48 Ainda na década de 1780, a Junta de Liquidação estava recebendo pelas vendas feitas em Angola mais de dez anos antes; ver ANTT, CGPP, Livro 395

49 Carrara observa este fenômeno, cf. CARRARA, Angelo. Minas e currais, passim. 
corriam nos mercados internos brasileiros. Daí que a depressão na década de 1770 afete também alguns setores da agricultura de exportação, talvez pela perda de liquidez da economia colonial, resultado da execução e cobrança de dívidas.

Ultrapassada a década de 1770, começaram a dar resultados as transformações institucionais pombalinas: foi incentivada a produção manufatureira na metrópole e diversificada a economia da colônia, marcando também a retomada das atividades na produção do açúcar e de outros produtos coloniais tradicionais. Destaque-se ainda o crescimento das exportações da região amazônica. Houve novamente uma mudança na estrutura econômica do Império e a recuperação nas remessas aos particulares da década de 1790, referida por Rita Martins de Souza, pode ser reflexo de um aumento da velocidade de circulação das moedas no interior do próprio Império português..$^{50} \mathrm{O}$ crescimento nos preços dos produtos coloniais foi decisivo, mas arrisco a dizer que na década de 1790 o centro dinâmico não era apenas a agricultura de exportação, mas um complexo econômico que unia as atividades manufatureiras na metrópole à agricultura do litoral do Brasil, particularmente na produção do algodão. Como reconhece Jorge Pedreira,

o impulso industrial promovido durante a última fase do governo de Pombal, que se prolonga sob o reinado de D. Maria, acaba por romper a associação entre surto industrial e conjuntura comercial depressiva que caracterizava anteriores iniciativas de fomento manufatureiro. As exportações, e não apenas a substituição de importações, adquirem um papel relevante, configurando-se uma vinculação entre a economia imperial e o crescimento, porventura modesto, da indústria. ${ }^{51}$

Algumas conclusões: em primeiro lugar, a crise do final do século XVII mostra o caráter "extrovertido" do açúcar: a crise foi motivada pela queda nos preços do açúcar, como um desdobramento da crise geral do século XVII. O modo como ela se desenvolveu aponta para a mesma direção: a escassez de moeda sentida primeiramente no centro metropolitano foi "exportada" para as periferias coloniais, muito provavelmente pela falta de crédito. Ao mesmo tempo, o modo desigual pelo qual se desenvolveu demonstra como a crise dependeu das circunstâncias econômicas de cada

50 É preciso notar que depois da crise da mineração Portugal interrompeu a tendência aos déficits com as nações estrangeiras, ver NOVAIS, Fernando. Portugal e o Brasil na crise do Antigo Sistema Colonial, p.322.

51 PEDREIRA, Jorge. Estrutura industrial e mercado colonial: Portugal e Brasil (1780-1830). Lisboa: Difel, 1994, p.62. Ver também MACEDO, Jorge. Problemas de história da indústria portuguesa no século XVIII, p.198 e ALEXANDRE, Valentim. Um momento crucial do subdesenvolvimento português: efeitos económicos da perda do Império Brasileiro. Ler História, n. 7, p.3-45, 1986. 
região açucareira, pois os custos na reprodução da economia escravista podiam agravar (Bahia) ou então diminuir (Rio de Janeiro) a intensidade da crise.

Já a crise das décadas de 1760-1770 explicita o ritmo particular da produção mineral, posto que todo o sistema econômico colonial dependia em grande parte das demandas geradas pela produção do ouro; é uma crise essencialmente colonial, pois tem início em Minas Gerais. Como bem atentou Carrara, não é possível aplicar o modelo explicativo do açúcar para a economia mineradora. Não obstante, o modo como a redução na produção aurífera afetou o sistema revela como a economia metropolitana e o tráfico de escravos estavam amarrados à produção do ouro, reagindo aos ritmos impostos desde os sertões mineiros. Esta crise, porém, também teve uma espacialidade desigual, com o descolamento da economia da região Amazônica e uma recuperação mais precoce de Pernambuco.

Para além do escopo do estudo das crises, é possível fechar aqui com as reflexões de F. Mauro: as flutuações econômicas do Brasil colônia seriam miséculaire, ou seja, a recuperação das depressões tenderia a ser mais acelerada em função de uma maior variedade de produtos para exportação; a baixa de um produto podia ser compensada pela produção de outro. ${ }^{52}$ Creio, porém, que esta interpretação pode ser ampliada para a longa duração do Império português, pois dos fins do século XV ao início do século XIX observa-se uma geografia econômica cambiante e uma fiscalidade plástica que acompanhou as modificações, do ouro da Costa da Mina, para a pimenta da Índia, do açúcar da Bahia e Pernambuco, para o ouro das Gerais. Como escreveu V. M. Godinho, a realeza e o Estado Português "alicerçam-se (...) na mercancia e na navegação oceânica", 53 alicerces que cambiaram de século a século. As conjunturas econômicas e fiscais do Império português eram conjunturas de produtos, mas também conjunturas espaciais.

\section{Apêndice 1: Dízimos}

Os dízimos vêm sendo usados como um indicador da produção agrícola pela historiografia econômica há algum tempo e a sua validade já foi discutida por diversos autores. Resumidamente, podemos dizer que pelos valores arrematados chega-se à expectativa dos contratadores em relação à

52 MAURO, Frédéric. A conjuntura atlântica e a Independência do Brasil. In: MOTTA, Carlos G. 1822: dimensões. São Paulo: Perspectiva, 1972, p.38-47.

53 GODINHO, Vitorino Magalhães. Finanças públicas e estrutura de Estado. In: Estudos: sobre a História de Portugal II. Lisboa: Livraria Sá da Costa, 1968, p.49. 
produção rural nos três anos que se sucediam à arrematação propriamente dita. Mas os números poderiam variar não apenas em razão do produto agrícola, mas também de acordo com as mudanças nas condições de arrematação, com a entrada de novos grupos mercantis e com as condições da cobrança do imposto, o que parece ser o caso da década de 1760 quando diversos contratos deixaram de ser arrematados no Conselho Ultramarino e passaram a ser leiloados nas provedorias locais. Vale então considerar mais as curvas no conjunto das regiões do que os números absolutos de uma ou outra praça. ${ }^{54}$

\section{Tabela 1}

Dízimos da Bahia, Rio de Janeiro e Pernambuco, 1677-1693 (em cruzados)

\begin{tabular}{lccc}
\hline Anos & Bahia & Rio de Janeiro & Pernambuco \\
\hline $1677-1678$ & 110.000 & 26.500 & \\
$1678-1679$ & 106.000 & 26.500 & 42.099 \\
$1679-1680$ & 96.000 & 26.500 & 44.100 \\
$1680-1681$ & 100.000 & 30.666 & \\
$1681-1682$ & 90.000 & 30.666 & \\
$1682-1683$ & & 30.666 & \\
$1683-1684$ & & & \\
$1684-1685$ & & & \\
$1685-1686$ & 110.000 & & \\
$1686-1687$ & & 43.333 & 45.000 \\
$1687-1688$ & 110.000 & 43.333 & 40.000 \\
$1688-1689$ & 66.000 & 43.333 & 20.000 \\
$1689-1690$ & & & 36.500 \\
$1690-1691$ & 86.000 & & 51.000 \\
$1691-1692$ & 90.000 & & 47.500 \\
$1692-1693$ & 84.000 & & 35.000 \\
\hline Fonte: CARRARA. Ângelo. Receitas e desesas da Real Fazenda no Brasil século XVII. anexo $1 . \mathrm{p} .126$
\end{tabular}

54 Autores que usam os dízimos como indicadores da produção rural SCHWARTZ, Stuart. Segredos internos, CARRARA, Ângelo. Minas e currais; LOPES, Gustavo Acioli. Negócio da Costa da Mina e comércio atlântico; CARRARA, Ângelo. Ouro, moeda e mercado interno; um modelo contábil da economia de Minas Gerais, 1700-1808, working paper, 2005. Consulte-se ainda a crítica ao uso dos dízimos de autoria de AZCUY AMEGHINO, Eduardo. Agricultura, ganadería y diezmos en el obispado de Buenos Aires, 1782-1802: una comparación infructuosa. In: _. La Otra Historia: economía, Estado y sociedad en Río de la Plata Colonial. Buenos Aires: Imago Mundi, 2002, p.253-292. 
Tabela 2

Dízimos da Bahia, 1750-1772 (em réis)

\begin{tabular}{ccc}
\hline & Trienal & Anual \\
\hline $1750-1753$ & 150.090 .000 & 50.030 .000 \\
$1753-1756$ & 189.600 .000 & 63.200 .000 \\
$1757-1760$ & 150.900 .000 & 50.300 .000 \\
$1760-1763$ & 150.930 .000 & 50.310 .000 \\
$1768-1769$ & - & 50.400 .000 \\
$1769-1772$ & 159.600 .000 & 50.400 .000 \\
\hline
\end{tabular}

Fontes: CARRARA, Ângelo. Receitas e despesas da Real Fazenda no Brasil, século XVIII, anexo 13B, p.214-216.

Tabela 3

Dízimos de Pernambuco, 1753-1777 (em réis)

\begin{tabular}{ccc}
\hline & Trienal & Anual \\
\hline $1753-1756$ & 53.100 .000 & 17.700 .000 \\
$1756-1759$ & 60.030 .000 & 20.010 .000 \\
$1760-1761$ & - & 14.000 .000 \\
$1761-1764$ & 48.000 .000 & 16.000 .000 \\
$1764-1767$ & 56.400 .000 & 18.800 .000 \\
$1768-1771$ & 48.000 .000 & 16.000 .000 \\
$1771-1774$ & 52.800 .000 & 17.600 .000 \\
$1774-1777$ & 64.700 .000 & 21.566 .667 \\
\hline
\end{tabular}

Fontes: CARRARA, Ângelo. Receitas e despesas da Real Fazenda no Brasil, século XVIII, p.253; e AHU, Avulsos, Pernambuco, cx. 130, doc. 9823, 13/07/1778, José César de Meneses (certidão inclusa).

Tabela 4

Dízimos do Rio de Janeiro, 1751-1775 (em réis)

\begin{tabular}{ccc}
\hline & Trienal & Anual \\
\hline $1751-1753$ & 72.060 .000 & 24.020 .000 \\
$1754-1756$ & 72.060 .000 & 24.020 .000 \\
$1757-1759$ & 78.360 .000 & 26.120 .000 \\
$1760-1762$ & 82.320 .000 & 27.440 .000 \\
$1764-1766$ & 85.365 .000 & 28.455 .000 \\
$1767-1769$ & 85.365 .000 & 28.455 .000 \\
$1770-1772$ & 86.400 .000 & 28.800 .000 \\
$1773-1775$ & 86.400 .000 & 28.800 .000 \\
\hline
\end{tabular}

Fontes: AHU, Contratos Reais, Cod. 298, Livro de registro dos contratos reais do Conselho Ultramarino. $3^{\circ}$ volume (1753 - 1771); AHU, Contratos Reais, Códice 1269 - Mapa dos Contratos Reais do Conselho Ultramarino (1641-1758); AHU, Avulsos, Rio de Janeiro, cx. 89, doc. 7782, Francisco Cordovil de Sequeira e Mello, 29/01/1770; GUIMARÃES, Carlos e PESAVENTO, Fabio. Os contratadores e os contratos do Rio de Janeiro colonial, 1769-1779: estudo de uma sociedade mercantil. In: CHAVES, Claudia Maria das Graças e SILVEIRA Marco Antonio. (orgs.). Território, conflito e identidade. Belo Horizonte: Argvmentvm, 2008, p.107-126. 
Um cálculo bastante simples permite obter uma estimava grosseira da tendência geral da economia colonial: reunindo a arrecadação dos dízimos da Bahia, Pernambuco, Rio de Janeiro e Minas Gerais ao quinto do ouro pode-se "testar" se a diversificação agrícola no Estado do Brasil compensou a queda na produção do ouro. Naturalmente é um cálculo puramente exploratório; basta considerar que o "quinto" e o "dízimo" deveriam absorver diferentes proporções da produção agrícola (10\%) e mineral (20\%). Na prática, porém, as coisas eram ainda mais complexas, pois a derrama procedida em 1763 e 1764 e em 1771 pode ter distorcido os valores ${ }^{55}$. Ademais, as possibilidades de descaminho do ouro eram seguramente maiores do que nos produtos agrícolas e o ouro em pó, principal moeda da capitania de Minas Gerais, não pagava impostos. Por outro lado, segundo Carrara, o dízimo do açúcar e cachaça era de apenas $5 \%$, além do que seria necessário considerar os ganhos dos contratadores que eram o produto da diferença entre o total arrecadado e a soma paga na arrematação, além dos próprios custos com a cobrança do dízimo que também deveriam ser deduzidos do total arrecadado. Mais uma vez, trata-se de se levar em consideração a tendência no conjunto dos tributos em que a queda no ouro não é compensada por uma agricultura estagnada.

Sobre as médias anuais dos dízimos é preciso dizer mais algumas coisas: como na Bahia e em Pernambuco os contratos iniciavam em agosto, nos anos em que vigiam dois contratos, por exemplo o ano de $1756 \mathrm{em}$ Pernambuco, considerei o contrato mais novo para estabelecer o valor daquele ano (ou seja, no referido exemplo, o triênio de 1756-1759, ao invés do triênio de 1753-1756).

Além disso, existem algumas lacunas na série, muito provavelmente resultados de equívocos nas fontes ou de hiatos entre um e outro contrato por causa de mudanças institucionais; estas também devem explicar a existência de alguns contratos de duração de apenas um ano. Procurei completar as lacunas utilizando os números dos anos posteriores. ${ }^{56}$ Por último, completei o período em que não houve arrematação de contratos na Bahia (1763-1769) com o valor de 50 contos anuais, um pouco abaixo do valor anual anterior e posterior.

55 Talvez seja este o caso da arrecadação fora da curva registrada em de 1766, fruto do ajuste no ano fiscal que deixou de iniciar em agosto naquele ano e talvez do lançamento da derrama (ver gráfico 1).

56 A saber, 1756 na Bahia, 1759 e 1767 em Pernambuco. 


\section{Gráfico 1}

Dízimos do Estado do Brasil (Bahia, Pernambuco, Rio de Janeiro e Minas Gerais) e quinto do ouro (réis), 1753-1771

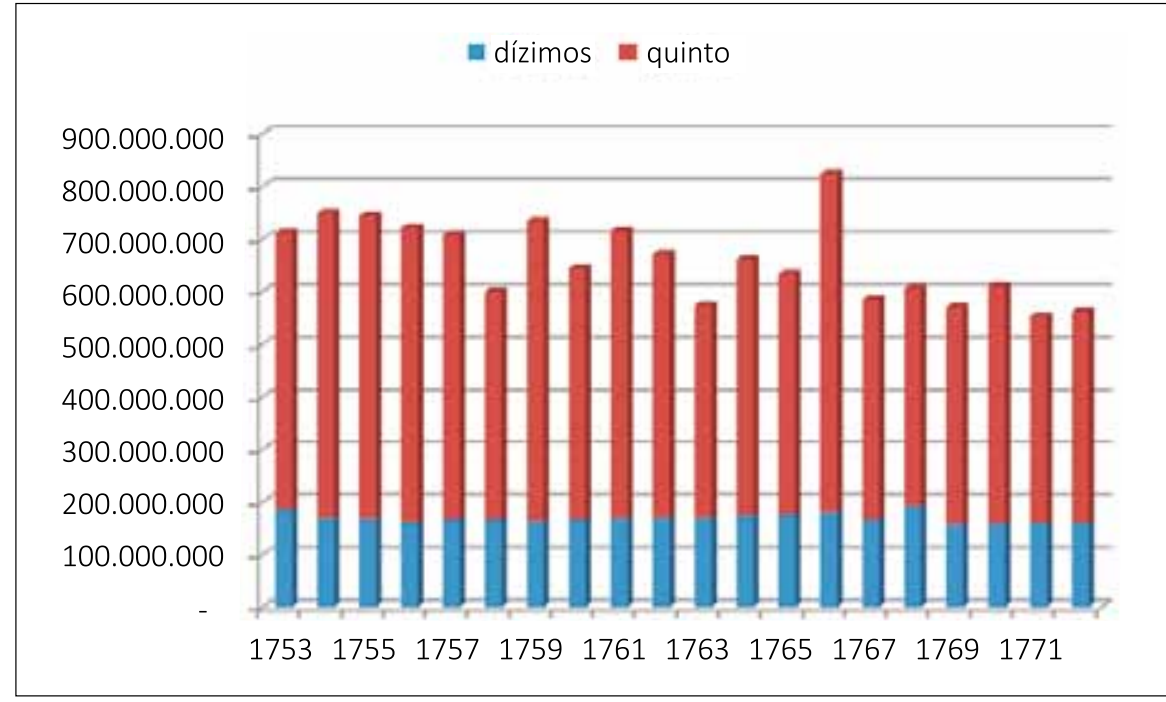

Fontes: Dízimos da Bahia, Pernambuco e Rio de Janeiro: ver fontes das tabelas 2, 3 e 4. Dízimos de Minas Gerais: MAXWELL, Keneth. A Devassa da Devassa: a Inconfidência Mineira: Brasil e Portugal, 1750-1808. Rio de Janeiro: Paz e Terra, 1977, anexo estatístico. Quinto do ouro: ESCHWEGE, Wilhelm L. Pluto Brasilienses. v.1 (1833). Belo Horizonte/São Paulo: Itatiaia/Edusp, 1979, p.201. O valor da arroba era de 4.915.200 réis, calculado pelo valor da oitava de ouro (1.200 réis) multiplicada pela quantidade de oitavas que continha uma arroba (4.096). Cf. CARRARA, Ângelo. Receitas e despesas da Real Fazenda no Brasil, século XVIII, p.24.

\section{Apêndice 2: Escravos exportados para o Brasil}

Os escravos são os principais indicadores do investimento na economia colonial. O gráfico 2, baseado nos dados do TSLTD, mostra uma queda no investimento nas décadas de 1760 e 1770 e uma retomada na década de 1780. Fica claro, porém, que a região Amazônica (Grão Pará e Maranhão) descola-se justamente neste período.

O gráfico 3 apresenta as exportações de Angola. Penso que ele revela mais bem a "conjuntura imperial" já que oferta de escravos no porto de Luanda dependia menos de condições "exógenas" ao próprio império; é preciso lembrar que o exclusivo possuía alguma efetividade no entorno de Luanda. ${ }^{57}$ Mais uma vez a depressão dos anos de 1760 e 1770 fica muito bem marcada.

57 Cf. LOPES, Gustavo Acioli e MENZ, Maximiliano M. Resgate e mercadorias: uma análise comparada do tráfico lusobrasileiro em Angola e na Costa da Mina (século XVIII). Afro-Ásia, n. 37, p.43-73, 2008, MENZ, Maximiliano M. "As geometrias do tráfico": o comércio metropolitano e o tráfico de escravos em Angola (1796-1807). Revista de História, São Paulo, v.166, p.185-222, 2012; e MILLER, Joseph C. The numbers, origins, and destinations of slaves in the EighteenthCentury Angolan slave-trade. In: INIKORI, Joseph E e ENGERMAN, Stanley L. (ed.). The Atlantic slave trade: efects on 


\section{Gráfico 2}

Escravos exportados para o Brasil, 1701-1810

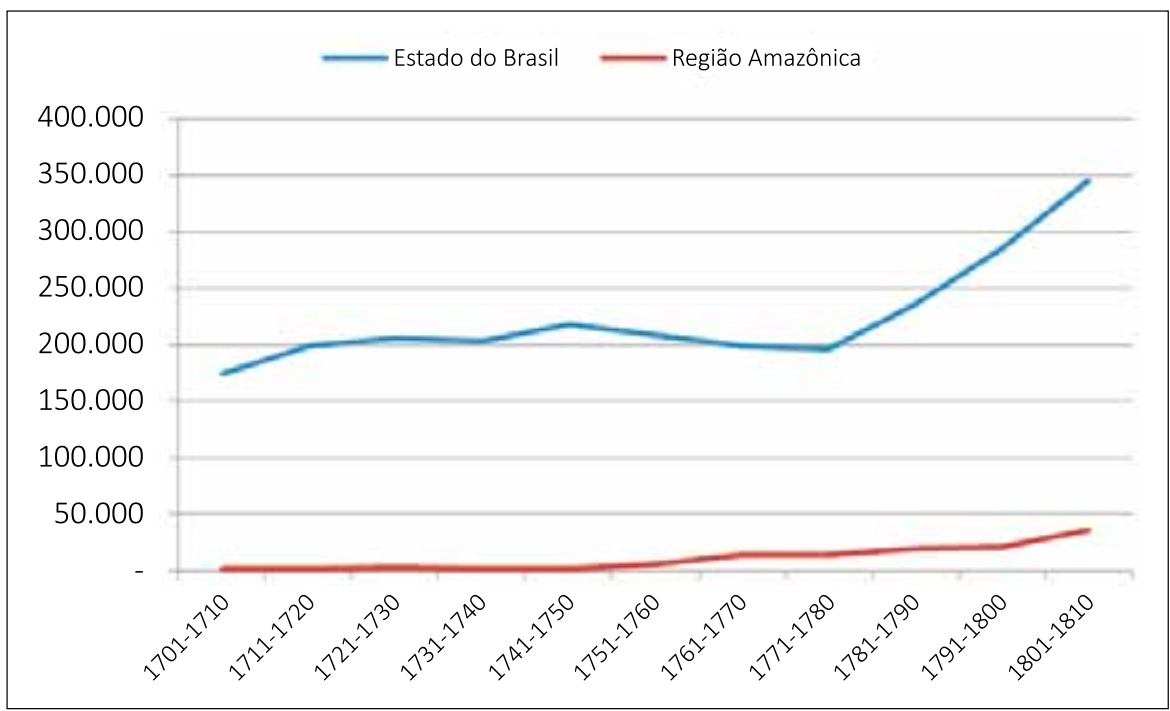

Fonte: TSLTD, http://www.slavevoyages.org/tast/assessment/estimates.faces. Acesso em: 3 jan. 02012.

Gráfico 3

Escravos exportados por Angola, 1756-1806

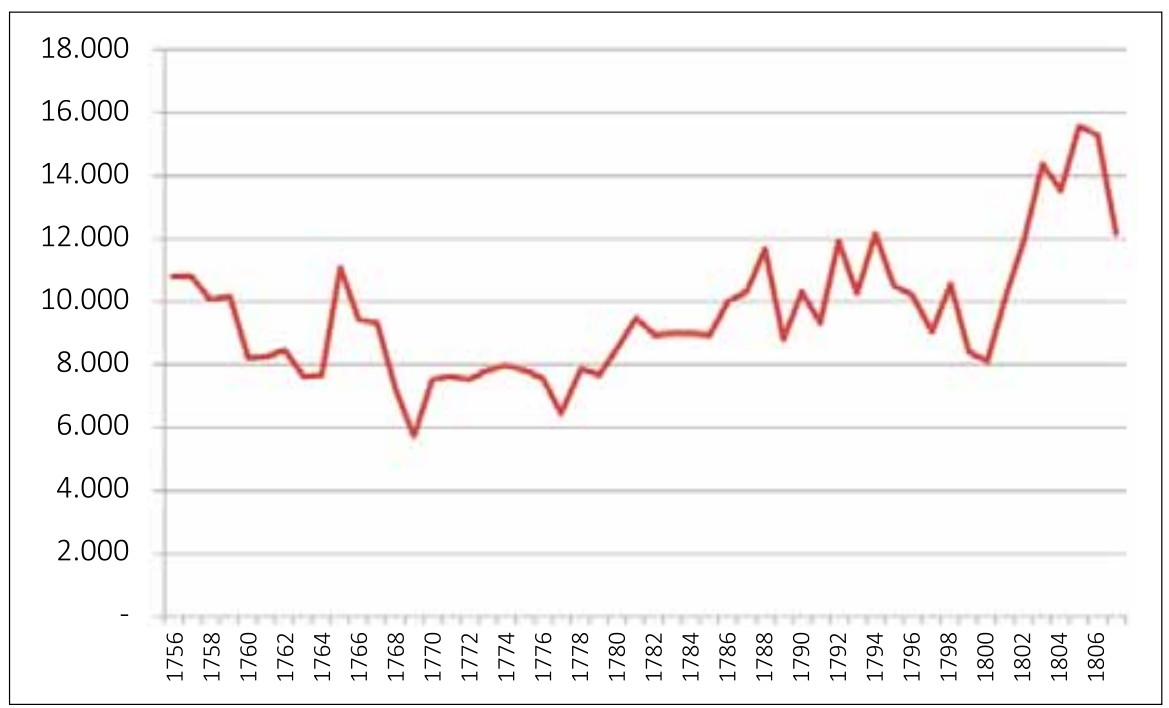

Fonte: CURTO, José. Álcool e escravos, quadros IV e VIII.

economies, societies and peoples in Africa, the Americas and Europe. Durham/London: Duke University Press, 1992, p. 77-116, que realça a importância do crédito e das instituições portuguesas em Luanda na sua conexão imperial. 